\title{
Malignant Bladder Paraganglioma
}

National Cancer Institute

\section{Source}

National Cancer Institute. Malignant Bladder Paraganglioma. NCI Thesaurus. Code C6416.

An extra-adrenal sympathetic parag ang lioma of the bladder that metastasizes to other anatomic sites. 